TURIZAM

Volume 16 , Issue 1

20-28 (2012)

\title{
Ethics in Providing Tourism Services by Travel Agents in Serbia
}

\author{
Ivana Mišković* \\ Received: September 2011 | Accepted: December 2011
}

\begin{abstract}
This paper attempts to answer the usually neglected ethical questions of the interaction between tourism workers and participants in tourism movements and users of tourism services in general. Contact with numerous people in the work place, dynamic work with customers, continuous phone calls and stress due to constant responsibility, are just some of the conditions which tourism workers encounter on the daily basis and which sometimes make them ask themselves: Am I really able to do this job? Will their behaviour with each customer be ethical? Will they be able to hide from the customers their stress, nervousness and mental fatigue? Have all the employees in travel agencies attended the training courses in communication with customers, or does everything depend on their own decisions and home upbringing? Is it worth taking risk and putting agency's reputation at stake? Which moral dilemmas do the tour guides encounter on the journeys? These are just some of the questions which will be put in the spotlight in this paper. The aim of this paper is to indicate the necessity to establish the codes of conduct for all professionals who are in direct contact with tourists.
\end{abstract}

Keywords: Ethics, Tourism, Services, Travel agencies, Communication

\section{Introduction}

Ethics is a well-known science in our civilization and numerous books have been written on this matter through the centuries. Ethical questions were first introduced to our civilization by the Greek philosophers, taking a form of religious norms of behaviour and today they still have the equal relevance. The contemporary understanding of what is ethical is mostly reduced to the modern man's individual vision which depends on numerous factors, such as home upbringing, personality, and the influence of the environment, especially in countries like Serbia, where ethical values are in deep crisis.

We should not consider tourism merely as an economic category, but also as a collection of human activities and interactions which influences everyone's everyday life. This paper will focus our attention specifically on the analysis of the ethical questions of selling tourism products, starting with advertising, and then the first, the second and all subsequent

* Kompas tourism\&travel doo, Bulevar Mihaila Pupina 15, 2100o Novi Sad, Serbia, e-mail: i.miskovico21@yahoo.com 
encounters with the customer, sales, follow through and finally, with communication after the accomplished journey. A number of practical examples will describe in a vivid way different situations in which the tourism workers and their customers can find themselves.

Methods used in this research are: interview with experienced travel agents, deductive method, research through survey of agency documents and notes.

\section{Business ethics of tourism companies}

Due to the fast growing competition, only those companies which adopt higher ethical standards and which try o meet even the smallest customer's needs, will be able to stay in the race. Although the majority of tourism companies tend to provide flawless services, it is impossible to totally eliminate the possibility of making mistakes, because there are numerous factors which influence their occurrences. The way in which the efforts are made to prevent errors and to smooth out their consequences, distinguishes successful companies from the unsuccessful ones. These efforts can be considered crucial in business conduct and they can be seen as a tendency to satisfy the customers' needs and to maintain their loyalty, as well as to maintain the company's good reputation.

The very fact that one is brought up properly does not provide enough arguments for the fight against countless challenges. Even the best workers can easily succumb to the negative influence of the competition, their colleagues, family problems, etc. They become fed up with their job, and over the years their personalities change. When we analyze the person in this context, we should take into consideration one's ability to control himself, and to react in the appropriate way in the critical situations, one's manageability, religion, age, working experience and nationality. The general manager should be the moral leader and a model to his/her subordinates. He should control their ethical behaviour as well as the company's business decisions. By imitating the behaviour of persons who have important roles in our lives, we learn how to be responsible. The importance of the general manager's role to his employees is doubtless, and consequently, the general manager's ethical attitude directly influences their own ethical behaviour.

Unfortunately, there are no official ethical codes of conduct for tourism organizations in Serbia, and those that have it, do not apply it to the necessary extent (Jovicic et al.,2OII).

\section{Advertising of tourism products}

When we are talking about marketing in tourism, the most common ethical dilemmas are those connected to the presentation and advertising of the tourism products and services. Examples of these are the photos of the hotels and the beaches digitally processed and manipulated that often appear in travel agencies' catalogues and on their web-pages. It is almost a rule that hotels will publish just the photos of their biggest and the most beautiful rooms on their websites, even if, in reality, they have several room categories. Is this the correct behaviour and who profits and who loses from it? The dissatisfied customer who will not again visit the same hotel and potentially spread bad rumours or the hotel (the agency) which sold the package to the customer and will perhaps have to deal with customer complaints or court proceedings? These are the typical ethical questions which the tourism workers encounter every day. Each unhappy customer will convey his/her negative impression to at least I3 potential travellers! (Lufthansa LCC Quality Standards, 2006) 


\section{Case study no. I : "Photoshop"}

In one renowned reservation system, designed for the professional use around the world, there is a presentation of a hotel in Novi Sad. Among the photos of the hotel's interior, the photo shown below can be found:

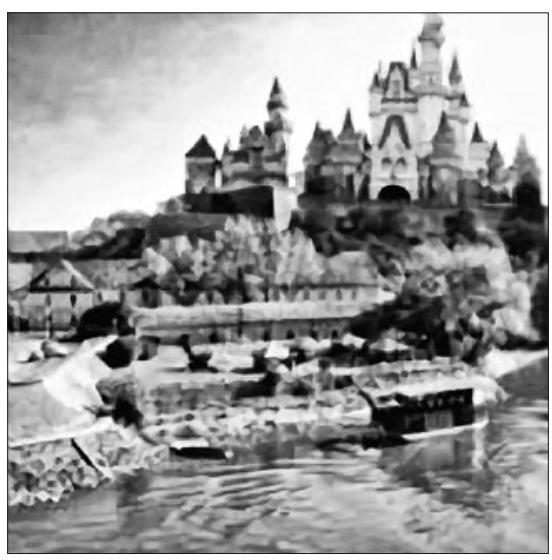

Figure 1. Petrovaradin Fortress

Source: http.www.hotelspro.com

The landmark of one European city, which is trying to insert itself onto the global tourist map, is ruined by this photograph.

If it is so easy to manipulate with the photos of the city's symbols, what is then being done with the photos of hotel rooms and apartments? How to deal with such situations and how to protect yourself from similar experiences? Could this also happen to you or to your customer? Some tourism experts recommend reading the comments of previous guests and users of tourism services written on the websites of the hotels and the travel agencies, and that is not a bad advice. Travelling to places recommended by our friends is also a good idea, but it is necessary to take into consideration the differences in tastes and needs, as well as the time that has passed from their last visit.

\section{Case study no. 2: "Non-existent package"}

A few years ago a scandal happened in our country. A travel agency had sold a great number of travel packages for one summer holiday destination, and when the travellers landed, the hotel refused to accommodate them due to "overbooking". Later, it turned out that the reason was that travel agency hasn't paid its debts to the hotelier. The travellers were left on their own to look for the accommodation on spot. This agency lost its tour operator license, but soon after, the same owner founded a new agency, with another name, and continued working at the same office location, with a same personnel.

It seems that everything is possible in countries where the law allows the entrepreneurs to continue their activity after committing fraud.

\section{Case study no. 3: Journey to Rome}

An advertisement is posted in newspapers and on television: ROME FROM IO EUR!!!

Seeing the advertisement, the customer comes to the travel agency and asks the agent for the plane ticket to Rome for IO EUR. The agent explained that he will also be charged for the airport taxes and for the ticket issuing, that IO EUR is the price for a one-way ticket, and that the customer will also need a return flight, and finally, the agent informs the customer that the total price is I2O EUR. The 
customer, struck by this information, asks the agent if she reads newspapers and watches television, accuses the agency of stealing customers' money..

\section{Ethics in communication with users of tourism services}

Tourists are willing to allocate more money for their vacations as compared to how much they spend in their place of residence for the same period of time. For them, that long awaited period of the year is a from of an escape from reality, something they have been dreaming of for months, as a separation from work and stress of the everyday life. When choosing a destination for their vacations, tourists unconditionally expect to get a maximum for the money they have paid, to be treated with respect and to have an unforgettably pleasant experience. While sometimes these expectations go beyond realistic possobilities, sellers and providers of tourist services must do their best.

A successful sale is not just a quantitative category, but also includes the ability of sellers to gain the trust of their costumers. Regardless of the company's reputation, customers relate to persons that inspire confidence. Sellers have to gain this confidence by ethically sound behaviour and sincere effort to meet all the client's wishes.

\section{Customer's first contact with travel agency}

The customer's first contact with the agency is achieved through marketing and advertisements in media or by word of mouth. That is usually the first time the customer hears the name of the agency or makes a visual connection to its logo. The first direct contact is usually by phone, or by visiting the website and finally by coming to the agency itself.

The first phone contact will leave the strongest impression on a client, therefore it's very important that it is pleasant and positive. The customer expects to feel appreciated and respected, not to wait on the line for more than Io seconds, not to have the line transferred more than once and also doesn't want to listen to irritating music whilst waiting on line.

\section{Case study no.4: Chinese whispers}

All the agents are busy doing their jobs. The customer is waiting for someone to pick up the phone. He is nervous because he urgently needs to book the plane tickets for tomorrow's flight.

Finally, somebody answers the phone, apologizing for not being able to transfer the line to someone from the airline service, because all the operators are busy. He asks the customer to call back a little bit later. A few minutes later, the same situation is being repeated. The customer loses his nerve, and searches for the number of another travel agency.

Situations like this happen every day, but they can be easily prevented. Companies involved in providing services and information, should install answering machines. In case where the agency does not have an automatic answering system, the phone should not ring more than four times before one of the agents answers it. Agent should not talk with his mouth full, not chew gum while talking, not talk simultaneously with other persons, speech has to be distinct and clear, without inappropriate phrases, speed of speech must be adequate. If the agent takes the message for his colleague, he has to check if the colleague has received it etc. (Lufthansa LCC Quality Standards, 2006). 
The first visit to the agency makes an impression on every customer. First of all, the agency's window should not be cluttered with colourful papers and ads, especially not with those in hand writing. Chaotic, untidy and dusty windows, absence of any concept in advertisement organization, etc. are unacceptable. These scenes can easily make the customer turn around and leave without even entering.

When entering the agency, the customer first notices the general atmosphere, the interior, the agents' appearance, sounds, smells, music, colours, etc. Smiles and immediate eye contact with the agent, even if the agent cannot to be of immediate assistance to the customer, will make a positive impression, especially if the agent signals to the customer to take a seat and wait for a moment.

Lack of wheelchair access ramps is also a common problem in almost all agencies in our country.

\section{Ethics in selling tourism products}

In dealing with a potential customer the most important thing is to be honest and accurate about the information provided. The customers want to feel secure and trust the agent. If he does not have certain information at the moment, the best thing to do is to apologize. It is extremely important to keep the promise and find an answer, otherwise, the damage could be immense: once lost, the customer's trust is more difficult to regain.

Comparison of competitive products should be done realistically and fairly. Criticizing others can easily cause damage to our selves, and it is not ethical. If the seller of the tourism product has any doubts concerning its quality or there is a possibility of its cancellation, he should warn the customer immediately. This way the any potential negative effects will be greatly reduced.

It is also risky to try to persuade the customer to pay for additional services, which most likely he will not need. The problems arise when it comes to complaints and demands for compensation. That is the defining moment which clearly shows how big of an effort the company is ready to make in order to preserve its good reputation.

\section{Case study no. 5: Holiday that meets your needs}

An agency has a fixed lease of a certain capacity in one resort in Greece. Sales are not going well. The general manager has arranged a meeting ands advised his employees to push for the sale of the rented object with the reduced price. The accommodation facility is in the centre of a tourist place, in a busy and noisy street, approximately 50 metres, as the crow flies, from the beach, but it takes about Io min. to reach the beach on foot, because it is necessary to walk around a fenced hotel which occupies a large part of the coast.

On the map published in the catalogue, the facility is marked at its actual position, but neither is the fenced hotel in the vicinity marked, nor is it mentioned that there are many bars and restaurants in the street, and very noisy until late at night.

An elderly married couple comes to the agency and asks for a peaceful place to spend their holiday with their two grandchildren. "That is exactly what we are looking for, they thought: comfortable, quiet, and almost on the beach", they thought while making the reservation.

Upon returning from the holiday, the couple filed a complaint.

Large tour-operators ask their customers fairly often (when they come to the agency) to fill in a questionnaire, composed of a dozen of questions about where, how and with whom 
they plan to spend their holidays or desired journey. The questionnaire also contains questions about the type of desired accommodation, its location, category, catering, transport and travel insurance. At the end of the questionnaire, the customer is asked to leave his personal data: date of birth, contact phone number and address, information about his profession, hobbies, and interests. This papers can be useful as written records of clients demands, as well as for future contacts.

\section{Relationship with the customers during the journey}

During the journey, the travellers often feel anxious and insecure. Foreign country, foreign people, fear of being lost, fear of theft, fear of physical attack and diseases and other stressful events or circumstances may be hindering factors during the journey. The tour guide, or the travel agency's representative becomes the only person who represents security, connection to "reality" and can be relied upon for assistance, day or night. He is obliged at any moment to know where his passengers are, whether they are safe, or they need something and at the same time to keep the whole situation under control during the journey.

The stress of working as a tour guide is illustrated in case studies in which former tourist workers, who travelled with the group as ordinary passengers, created unpleasant situations for the actual tour guides in order to observe their reactions. Certainly, they are not the only ones to do it - there are people who enjoy testing someone's patience.

\section{Case study no. 6: A pilgrim to one's destiny}

One passenger, a former tour guide, during a visit to Israel, was pretending to be lost and robbed, was separating from the group during sightseeing, and was creating unpleasant scenes at the airport.

Upon returning to Belgrade, he thanked the tour guide for her patience and announced that he had always dreamt of ill-treating someone "as he had been mistreated during the years".

Tourists want to relax and have fun during their holidays, which is to be expected, but that entertainment could have consequences for the destination It is the tour guides' moral responsibility to inform their customers about acceptable norms of behaviour at certain destination, and inform them about the local culture and customs before and during the journey. At the end of each tour the guide should thank the passengers for their trust in the agency. He could ask them to fill in a questionnaire where the passengers could express their opinion regarding the accommodation, the sights, the services, as well as offer their suggestions for any changes to the itinerary, and which destinations they would like to visit in the future.

\section{Case study no. 7: "Let me see Tahiti, and then I can die"}

When he was young, one gentleman from Zagreb saw a TV show on Tahiti, which left a great impression on him. Since he did not have children, he decided each month to put aside a certain amount of his modest income and save it. When he got older, he realized that he had saved enough money for a journey of his dreams, and he paid for a twenty day travel package to the Pacific islands.

The day when they were returning from Tahiti, the gentleman was standing on the deck, waiting for his turn to disembark, when suddenly a wire that was holding the sail unhooked, hit him on the head, and killed him on the spot.

The ethical dilemma of the tour guide reached its peak. Death of the passenger is the worst thing that can happen to a tour guide. Corpse transport procedures, complicated administration in a foreign 
country, and continuation of the trip, which had not ended for the other passengers, had to be coordinated. The family of deceased was unable to bear the costs of corpse transportation, so tour guide had to organize the funeral right there and then.

Each tour guide and group leader has to receive adequate training for reactions in critical situations at the beginning of his career, and has to obtain a license. Every unpleasant situation will become even worse given an inappropriate or delayed reaction.

\section{Reacting on the complaints and appeals of passengers and communication with the passengers after the journey}

As mentioned earlier, the ways in which efforts are made to prevent errors and to smooth out their consequences, distinguishes successful companies from the unsuccessful ones.

Conduct, politeness and evident efforts which the employees make in order to resolve a problem, show the level of their ethical status and form an image of reliability of the entire company. The efforts that are made must have visible results - otherwise, everything might appear as staged. An unsatisfied passenger represents a potential "bomb" full of negative comments and emotions, and its explosion could seriously damage the company's reputation, so it is necessary that tourist agents are capable of recognizing critical situations and taking emergency actions to resolve problems. Action must be IMMEDIATE!

Case study no. 8: "Who is right (I)?"

A customer booked hotel accommodation in one Austrian ski resort at the agency. He insisted on the facility belonging to a certain hotel chain. The agent confirmed the reservation, the passenger signed the travel contract, and collected the voucher in rush, without checking the voucher data.

A few days later, the agent received the phone call from the customer who was desperate for help. In fact, the booked hotel belonged to the desired hotel chain, had the desired name, but was situated in another ski resort, almost $300 \mathrm{~km}$ away, in the snow swept Alps.

Case study no. 9: "Who is right (II)?"

A customer booked a plane ticket by phone, the reservation was sent to him by e-mail then he collected it in person.

The day before the trip, customer returns to the agency claiming that the issued ticket was not for the date he wanted. He accuses the agency of mistaking and the following dialogue takes place:

- I asked for the return on April I $2^{\text {th }}$, and you gave me the ticket for the $13^{\text {th }}$ !

- But, Sir, your reservation was for April $13^{\text {th }}$ from the beginning, besides the reservation was also sent to your email. Why didn't you call us immediately?

- I didn't noticed. I saw it just yesterday, but I am travelling with your agency for years, this should not have happened to you!

- All right. According to the ticket conditions, you are able to change the date of flight with an additional payment of I2O EUR.

-Excuse me?! Who has to pay I2O EUR? Me, or you who made the mistake? Please, call your supervisor immediately!

Unfortunately, unpleasant situations like this are very common in practice. People are not ready to admit their mistake, and they will do anything, using any means possible, to 
turn the situation to their advantage. An agent has to remain cool-headed and has to treat the customer with the respect whatever the circumstances are. How he will react in such situation depends on his resourcefulness, character, upbringing and personal experience. In any case, in order to prevent such situations, the agents should protect themselves by providing as many written proofs as possible, which show that the customer had agreed with the purchase, and whenever possible, that should be confirmed by the signature.

Passengers' complaints are not always realistic. Sometimes the customers complain that there were jellyfish in the sea and therefore, they could not swim for two days, that the hotel was excellent, but their room had a view of a construction site or of a graveyard, that on a plane they were seated close to the toilet, etc. Those situations are not always predictable, and the agency should not be held responsible for them. It depends on the agent's experience whether he will be capable to recognize potential risks and to warn the passenger, as well as to book in advance a certain room or a seat on a plane.

Practice has shown that an insignificant number of satisfied passengers will contact the agency after the journey, to thank and congratulate them for good organization. The next time they visit the agency is when they are planning a new journey. Often, they will recommend the agency to their friends. The situation with dissatisfied passengers is completely different - the vast majority of them will "raise the alarm" as soon as they return.

Some agencies have the policy to contact their former passengers at least six times a year, sending short appreciation letters upon returning from the journey is ethically correct and is a good marketing strategy.

\section{Case study no. IO: Mrs Nervous Doctor}

There are people who, during the journeys or during the preparation for them, are followed by "bad karma", as it is said in jargon. One very respected doctor is among them. At each of her hotel bookings, plane tickets, transfers or any other service, the agency faced problems which normally rarely happen, such as overbooking, cancelled flight, driver who was late, etc.

The same lady travelled with the same agency to London. From the start, she has complaining: on the plane seat, roommate, hotel location, she separated from the group and got lost, the tour guide neglected her, and so on. On the way back, the guide distributed questionnaires to the passenger. Of course, she wrote positive comments and continued to travel with the same agency.

By analyzing surveys and completer questionnaires, the agents should create their personal, as well as company's databases, from which they could obtain, on a daily basis, information regarding regular customers' birthdays, important dates for corporate customers, etc. Sending of birthday and holiday cards, letters of gratitude for loyalty, discount coupons, organizing raffles, parties, presentations of offers for the upcoming season, and similar activities, can be considered an excellent ethical and marketing strategy if properly designed and executed.

\section{Nurturing customer's loyalty}

In order for the customer to remain loyal to the agency it is necessary to nurture a good business relationship and pleasant interpersonal contacts, so that they feel respected and appreciated.

Numerous agencies organize holiday parties with raffles, or they even have personal reward systems. These actions motivate customers to favour certain service providers. However, these reward systems should be ethically correct. 


\section{Case study no. II: Who is going to Greece on holidays?}

The agency traditionally concedes its unoccupied apartments in Greece, free of charge, to its most valued customers. The agency sends a letter to a corporate customer stating that they would gladly give a free of charge tour package to one of their employees, in order to express a gratitude for a good cooperation.

Soon afterwards, the agency receives a rather unpleasant response from the manager of one large pharmaceutical company, in which she demands that the agency stops sending such letters to her company, with the explanation that she cannot favour and choose one of her employees over others, and she considers the agency's offer inappropriate.

\section{Conclusion}

Tourism has to be analyzed not only as an economic, but also as a sociological and psychological phenomenon. It creates countless connections between buyers of tourism services and all those who are involved in their providing. Tourism is one of the global industries, which has a great impact on people, and therefore, our goal should be to protect ourselves and prepare our young colleagues to predict and prevent unpleasant situations, and thus, keep our clients loyal and satisfied.

In this paper, using typical examples from an everyday practice, some situations which tourist workers and their customers can encounter any time were shown. Extensive working experience and adaptability are mandatory for resolving critical situations quickly and positively to both parties.

In order to gain that experience as quickly and as painlessly as possible, it would be useful to introduce the young tourist workers, at the beginning of their careers, to the positive, as well as to the less pleasant aspects of the relationships with customers. Greater the practical knowledge they gain at the beginning, the better results they will have in the future. If we consider it from the ethical point of view, it is necessary to always put yourself in a position of the other person.

\section{References}

Dramond, Dz., Bein, B. (2OOI): Bussines Ethics, CLIO, Belgrade.

Schoefer, K. I., Ennew C. (2004): Emotional Responses to Service Complaint Experiences: The Role of Perceived Justice. Journal of Travel \& Tourism Marketing, I7(I): 83-9I.

Putting Ethic into Practice: Tourism-an Ethical Issue (2000), Tearfund International Learning Zone.

Lufthansa LCC Quality Standards (2006): Total Quality Management.

Jovicic, A, Pivac, T, Dragin, A. (2OII): Ethical Conduct of Employees in Tourist Organizations in Novi Sad (Serbia), Turizam I5 (4): I35-I47, Novi Sad.

www.bnet.com (downloaded on O2.08.2OII)

www.hotelspro.com (downloaded on 29.08.2OII) 